\title{
Experimental Combined Numerical Approach for Evaluation of Battery Capacity Based on the Initial Applied Stress, the Real-Time Stress, Charging Open Circuit Voltage, and Discharging Open Circuit Voltage
}

\author{
Liu Yun, ${ }^{1}$ Biranchi Panda, ${ }^{2}$ Liang Gao ${ }^{\circ},{ }^{3}$ Akhil Garg $\mathbb{D}^{1},{ }^{1}$ Xu Meijuan, \\ Dezhi Chen, ${ }^{1}$ and Chin-Tsan Wang ${ }^{5}$ \\ ${ }^{1}$ Intelligent Manufacturing Key Laboratory of Ministry of Education, Shantou University, Guangdong, China \\ ${ }^{2}$ Department of Mechanical Engineering, Universidade de Lisboa Instituto Superior Tecnico, Portugal \\ ${ }^{3}$ State Key Lab of Digital Manufacturing Equipment \& Technology, \\ School of Mechanical Science and Engineering, Huazhong University of Science and Technology, Wuhan, China \\ ${ }^{4}$ Department of Civil Engineering and Architecture, Guangxi University, Guangxi, China \\ ${ }^{5}$ Department of Mechanical and Electro-Mechanical Engineering, National I-Lan University, ILan, Taiwan
}

Correspondence should be addressed to Akhil Garg; akhill@e.ntu.edu.sg

Received 11 June 2018; Revised 19 September 2018; Accepted 26 September 2018; Published 23 October 2018

Academic Editor: A. M. Bastos Pereira

Copyright (C) 2018 Liu Yun et al. This is an open access article distributed under the Creative Commons Attribution License, which permits unrestricted use, distribution, and reproduction in any medium, provided the original work is properly cited.

\begin{abstract}
With the intensification of energy crisis, considerable attention has been paid to the application and research of lithium-ion batteries. A significant progress has also been made in the research of lithium-ion battery capacity evaluation using electrochemical and electrical parameters. In this study, the effect of mechanical characteristic parameter (i.e., stack stress) on battery capacity is investigated using the experimental combined numerical approach. The objective of the proposed approach is to evaluate the capacity based on the initial applied stress, the real-time stress, charging open circuit voltage, and discharging open circuit voltage. Experiments were designed and the data is fed into evolutionary approach of genetic programming. Based on analysis, the accuracy of the proposed GP model is fairly high while the maximum percentage of error is about $5 \%$. In addition, a negative correlation exists between the initial stress and battery capacity while the capacity increases with real-time stress.
\end{abstract}

\section{Introduction}

With the reduction of traditional energy, the popularity of alternative energy sources is increasing day by day. The application of lithium-ion battery in electric vehicles is one of the great steps towards the mitigation of environmental problem with sustainability. As an efficient source of off-grid power system, lithium-ion batteries have been successfully applied on laptops, mobile phones, smart watches, and various medical and nonmedical instruments. Considering that the replacement of such kind of battery is costly, it is of immense importance to increase the durability of lithium-ion battery. Overcharge and overdischarge, which usually lead to deterioration of battery internal chemicals and permanent loss of internal active materials, are the main cause of the capacity fade of batteries [1]. For ensuring the safe and efficient operation of the electrical equipment with lithium-ion battery as the energy supply system, it is necessary to monitor the capacity of the battery in real time with acceptable accuracy. State of charge (SOC) and state of health $(\mathrm{SOH})$ have been widely studied as two main indicators evaluating the status of batteries. These two estimation parameters are both defined on the basis of the concept of battery capacity. Numerous researches related to battery capacity have been done in recent years. Madeleine Ecker et al. [2] studied the impact of temperature and state of charge on impedance rise and capacity loss based on the experiment data. An impedance-based electric-thermal 
model was proposed and coupled with the aging model to simulate the dynamic interaction between battery aging and thermal and electrical behaviour. To improve the estimation accuracy and efficiency of $\mathrm{SOH}$ of lithium-ion battery, Cai et al. [3] proposed a dynamic information extraction method based on a fast-discrete wavelet transform. Results show that the maximum error of $\mathrm{SOH}$ can be within 0.113. Chao Hu et al. [4] applied the improved Kalman filter method to evaluate the SOC and capacity. The key points in their research include a method for estimating SOC and capacity based on time scale separation and a scheme for accurate and stable capacity estimation. Huang et al. [5] develop a model for online, simultaneous SOC, and SOH estimations of Li-ion batteries. The instantaneous discharging voltage $(\mathrm{V})$ and its unit time voltage drop ( $\mathrm{V}^{\prime}$ ) are carried out as the model parameters. It is found that the $\mathrm{SOH}$ equation has a linear relationship with the correction factor $1 / \mathrm{V}$ 'times. Chen Z. et al. [6] used genetic algorithm (GA) to build the battery model and evaluated the $\mathrm{SOH}$ of battery. Modelling parameters include the diffusion capacitance in real time using measurement of current and open circuit voltage as well as terminal voltage of the battery. Furthermore, temperature influence on battery $\mathrm{SOH}$ was considered. Most of previous studies focused on the relationship between battery capacity and the electrical parameters (voltage and current), the chemical parameters (impedance spectrum), and other parameters like temperature $[7,8]$. In the context of methods for evaluating the performance of battery performance researchers have designed a specific calculation model for lithium-ion batteries by combining experiments and finite element methods (FEM) [9-11]. The mechanical properties of each component of lithium-ion battery in different environments are also studied [12]. The battery is simplified as a jelly roll for a more efficient analysis on the mechanical characteristics [13-15].

In the context of research of local mechanical parts (anode, cathode, electrolyte, shell, etc.), the mechanical properties of the materials of each part and their relationship with the chemical properties of the batteries have received greater attention $[16,17]$. So far, it is still a great challenge to establish an accurate model between mechanical properties of local components and the capacity because of the diversity and complexity of materials. For example, the pressure on the separator changes with the aging of the battery [18]. The porous size of the electrode, the pressure in the manufacturing process, and the electrolyte around it also affect its mechanical properties [19]. Recently, researchers have paid greater attention to study the fundamental relationship of mechanical parameters (stack stress) and the battery capacity. Stack pressure is a compressive stress produced during the manufacturing process of lithium-ion battery [20]. It was found to be able to be applied to evaluate $\mathrm{SOH}$ and SOC of batteries [21]. The value of stack stress is found to change for every cycle of charge and discharge under given applied load conditions. Therefore, it shall be interesting to explore the fundamental effects and establish a mathematical relationship of mechanical stack stress on the battery capacity. The current study proposes an experimental combined numerical approach on lithium-ion batteries to investigate the relationships between the capacity and the initial applied stress, real-time stress, charging open circuit voltage, and discharging open circuit voltage. Later, artificial intelligence (AI) method of genetic programming (GP) was applied in the modelling process to gain deeper understanding of the effects between the capacity and the independent design variables. The findings from the study will pave the way for the design of new battery technology that incorporates the sensors around battery which measures stress and temperature to accurately estimate the battery electrochemical performance.

\section{Research Problem Statement}

This section discusses the research problem on studying fundamental and finding the relationships between the capacity of the lithium-ion battery and the initial applied stress, the real-time stress, the charging open circuit voltage, and the discharging open circuit voltage. During normal operation of battery packs in the electric vehicle, the irreversible unwanted chemical and physical changes in batteries result in loss of active metals (lithium ions) and irreversible expansion of electrodes which lowers the stiffness of the battery. The increase in expansion of the electrode every cycle can be attributed to the accumulation of stress and development of strains in the battery (Figure 1). Therefore, measuring the stack stress along with temperature of the battery can be related to its capacity and SOH. Hence, in addition to the temperature, it is important to develop a scientific study to explore the means of quantifying the relationship of capacity with respect to the mechanical parameter such as the stack stress. Determination of the relationships requires the formulation of an accurate mathematical model that can precisely represent the nature of the data. The model is expected to be an expression for capacity consisting of four independent variables (initial stress, real-time stress, charge OPC voltage, and discharge OPC voltage, respectively).

\section{Experimental Details of Lithium-Ion Battery}

This section describes the experimental details of measuring the capacity of Li-ion batteries as a function of mechanical stack stress. The complete description is listed in steps as below:

(1) Stress sensor, HT-7311S3, HT-sensor, China: the stress sensors can measure a force up to $0.33 \mathrm{MPa}$.

(2) Steel container: each set consists of a small steel plate, a hollow base holding the battery cell and four bolts connecting the two parts. The container is shown in Figure 2.

(3) Data acquisition system, as shown in Figure 3.

(4) Electronic load EBC-A10H, ZKE, China, as shown in Figure 3.

(5) Lithium-ion battery, ICR18650-26F, Samsung, Korea. Battery specification is given in Table 1 .

As shown in Figure 3, the batteries are placed in the steel containers and undergo through charge-discharge cycles controlled by the electronic load. The stress data collected by 


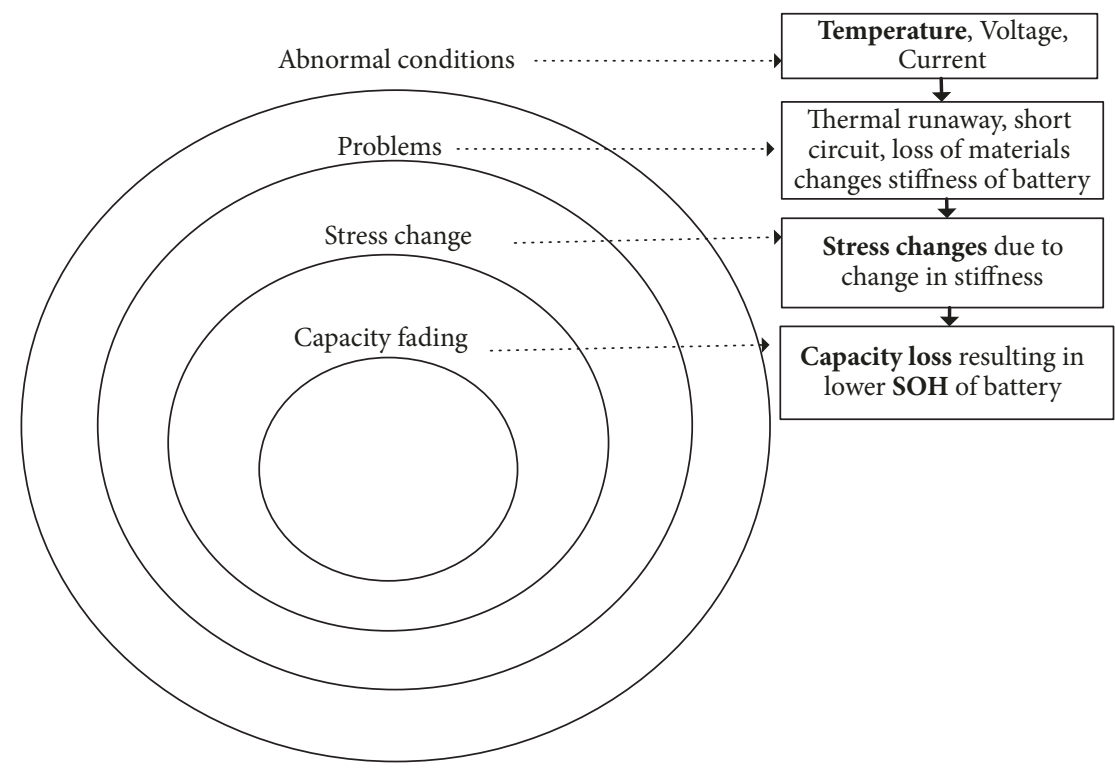

FIGURE 1: Figure showing the capacity fading of the battery because of abnormal operating conditions including the change in its stack stress.

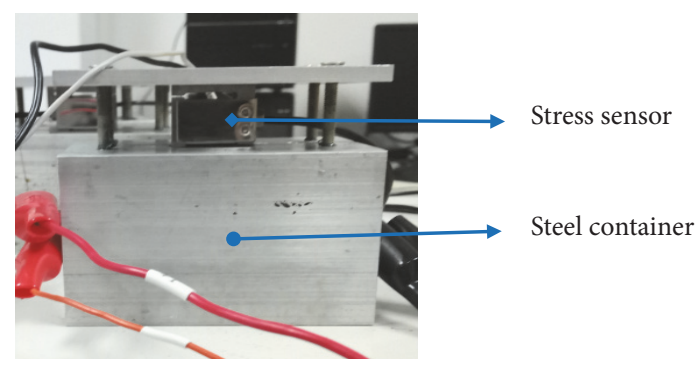

FIGURE 2: Stress sensor and Steel container.

TABLE 1: Specification of the lithium-ion battery cell used in the experiment.

\begin{tabular}{lc}
\hline Parameters & Value \\
\hline Operating voltage range & $2.75-4.2 \mathrm{~V}$ \\
Type & 18650 \\
Size & $\varphi 18 * 65 \mathrm{~mm}$ \\
Capacity & $2600 \mathrm{mAh}$ \\
Nominal voltage & $3.6-3.7 \mathrm{~V}$ \\
\hline
\end{tabular}

the stress sensor is imported to the computer via the data acquisition system before further processing. In this study, the batteries are divided into three groups with different initial stress applied on the battery. The initial stack pressure on the battery during its manufacturing stage is of the range 0.1 to $1 \mathrm{MPa}$ [20]. The initial stress is controlled at $0.098 \mathrm{MPa}$, $0.196 \mathrm{MPa}$, and $0.294 \mathrm{MPa}$ (the corresponding mass is $3 \mathrm{~kg}$, $6 \mathrm{~kg}$, and $9 \mathrm{~kg}$ ), respectively, by adjusting the bolts in the steel container. The surrounding temperature of the experiment is maintained at $20-25^{\circ} \mathrm{C}$ in a constant temperature box. Before applying the initial load on the battery, every battery is discharged to the cut-off voltage of $2.75 \mathrm{~V}$ at the rate of $0.5 \mathrm{C}$
(1.3 A). The following steps are the procedure for a single cycle of charge-discharge of the battery.

Step 1. Constant current charging procedure at rate of $0.5 \mathrm{C}$. When the voltage reaches the charging cut-off voltage of 4.2 $\mathrm{V}$, the constant voltage charging mode is applied until the charging current is less than $0.05 \mathrm{~A}$, which implies that the battery is fully charged.

Step 2. Open circuit for 30 minutes.

Step 3. Constant current discharging procedure at rate of $0.5 \mathrm{C}$ until the battery voltage drops to $2.75 \mathrm{~V}$ (discharge cutoff voltage).

Step 4. Open circuit for 30 minutes.

After implementation of these four steps, the experiments were conducted sequentially and, then, cycle around 30 times. The experiments were then repeated for verifying the validity of the result.

The listed steps are repeated for around 200 cycles for each battery cell. Data is collected and preprocessed in the computer before modelling.

\section{AI Methodology: Genetic Programming}

Genetic programming (GP) [22] is an evolutionary AI method in modelling of complex systems. As per principal of "survival of the fittest", GP simulates the evolution of the solutions with the best one is more likely to retain. Compared to response surface method (RSM), the advantage of GP is the automatic modelling process without any assumption of the structure of the model. Therefore, GP is adopted in this study to build the model for battery capacity. A total of 1443 data samples are fed into GP framework. $80 \%$ of 


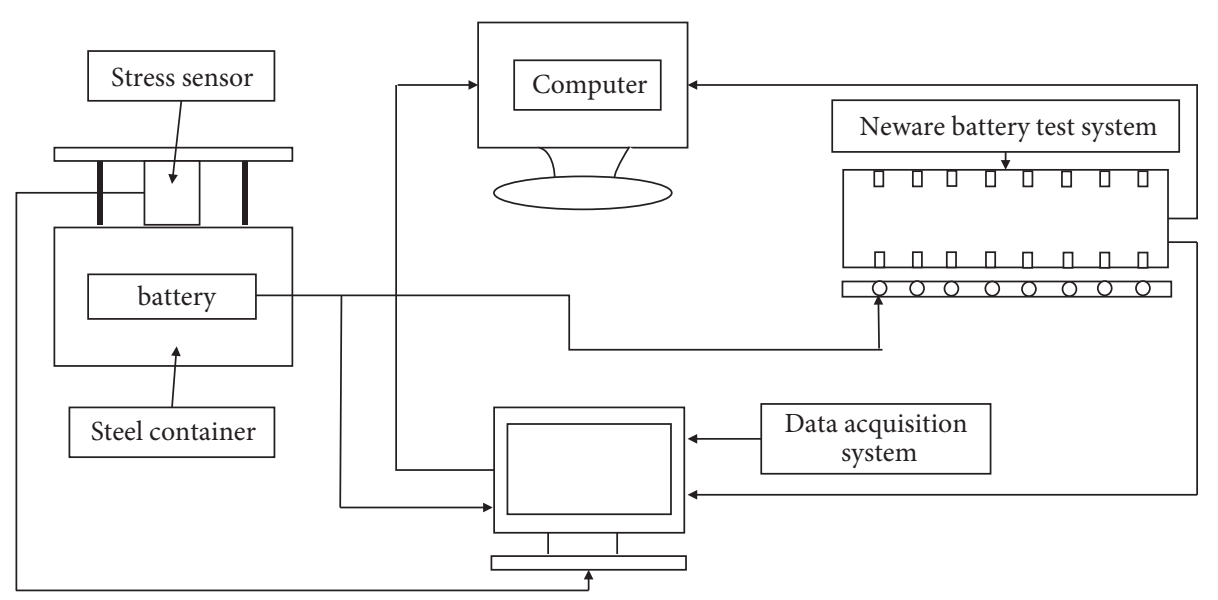

(a)

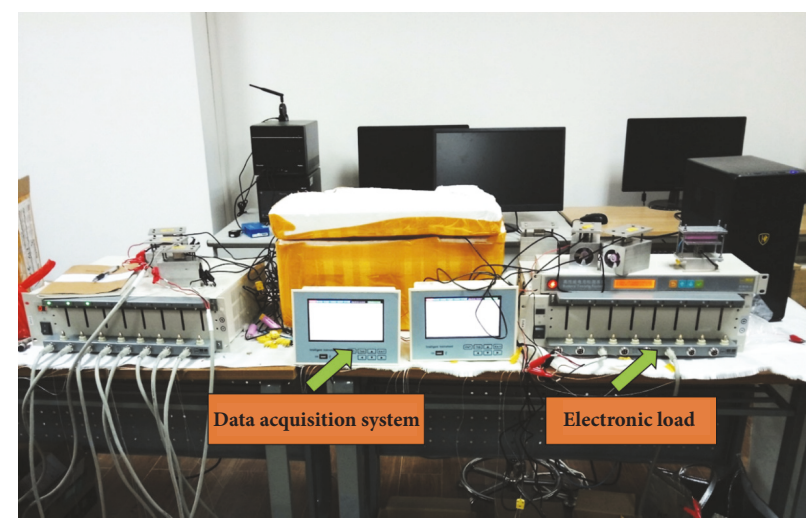

(b)

FIGURE 3: Schematic layout of the experimental setup.

the experimental data is imported as the training group while the remaining $20 \%$ is imported as the testing group. The parameter settings are set based on a trial-and-error approach. The population size and the number of generations are set to values of 1,000 and 500, respectively. The maximum depth of each tree and the maximum genes of model are both set to 3 in order to simplify the model. Generally, the low values of these two parameters can avoid the problem of overfitting of the models. The crossover, mutation, and direct reproduction probabilities are taken as values of $0.85,0.1$ and 0.05 , respectively $[23,24]$. Root mean square error (RMSE) and mean absolute percentage error (MAPE) are selected to be objective functions which conclude the performance of the models. The modelling of GP is carried out using MATLAB 2014b [25].

\section{Results and Discussion}

During the evaluating process of applying GP, the quality of an individual solution or its performance is measured by a fitness function value. The fitness function is a measure of the fit of the individual or model to the given data. The most commonly used fitness functions in GP are root mean square error (RMSE), mean sum of squared error (MSE), mean absolute percentage error (MAPE), and correlation coefficient $\left(\mathrm{R}^{2}\right)$. The lower the value of the fitness function, the better the quality of the solution or individual. In this section, the best performance of the GP model was selected with the minimum values of RMSE and MAPE.

Figure 4 shows the goodness-of-fit of the GP model. It can be observed from Figure 4 that most data points lie near the regression line $\mathrm{y}=\mathrm{x}$ (the red bold line in the figure), which indicates the predicted values calculated using the GP model slightly deviated from the experimental values. The small difference between the estimated values and the actual values validates the accuracy of the proposed GP model.

Based on the best model obtained, the relationship between output (capacity) and input parameters (initial applied stress, real-time stress, discharge OPC voltage, etc.) is qualitative. For the purpose of detecting the effect of each variable on capacity, $2 \mathrm{D}$ plots estimation are carried out. The Y-axis is the predicted value of capacity, which was generated by the GP model. While for the X-axis, the value of variables are original from experiment, for example, Figure 5(a) or set at the special range according to the analyzing requirement, for example, Figure 5(b). The evaluation methodology is that when considering one parameter of inputs as the analysis variable, other input parameters are set to mean value. Since 


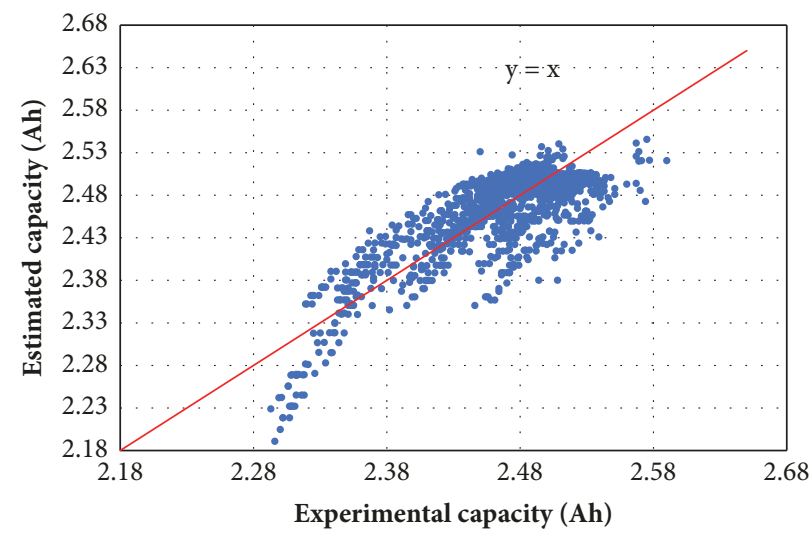

FIGURE 4: Goodness-of-fit of the mathematical model generated by genetic programming.

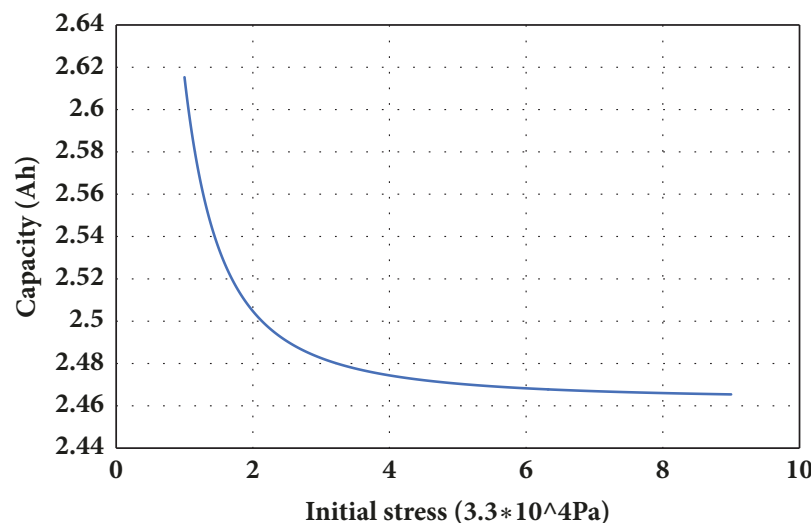

(a)

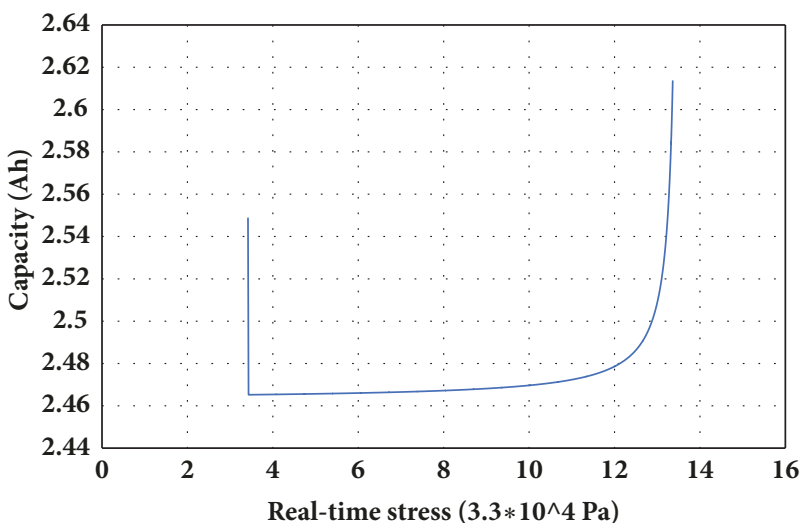

(b)

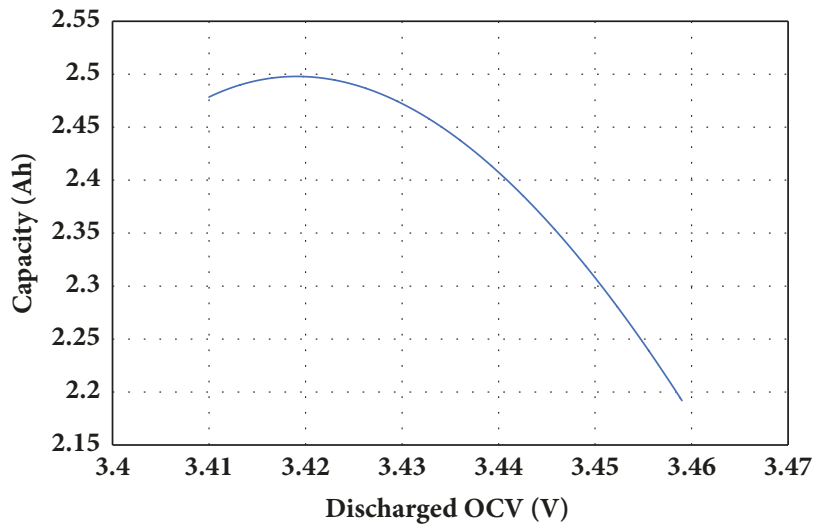

(c)

FIGURE 5: The estimation of the relationship between predicted capacity and each input parameters (initial applied stress, real-time stress, and discharge OPC voltage).

the GP model has determined the relationship between the input parameters and the output, for each independent variable, the Y-axis has a corresponding value. Thus, $2 \mathrm{D}$ plots can be obtained. Figure 5 shows the effects of each independent variable on the cell capacity. There are only three plots for the parametric analysis because the GP model consists of only the first three inputs excluding the charging open circuit voltage. It can be concluded from Figure 5(a) that there is a negative correlation between the initial stress and the cell capacity. A sharp decline is observed when the initial stress is less than $0.033 \mathrm{MPa}$, after which the declining trend slows down. Once the initial stress reaches $0.132 \mathrm{MPa}$, the trend can hardly be noticed. A completely converse trend is observed for real-time stress in Figure 5(b). The cell capacity experiences a slight increase with real-time stress in the range between $0.089 \mathrm{MPa}$ and $0.33 \mathrm{MPa}$ and rises rapidly after the value of $0.33 \mathrm{MPa}$. The abrupt segment around $0.089 \mathrm{MPa}$ appears probably because of the noisy data and can 


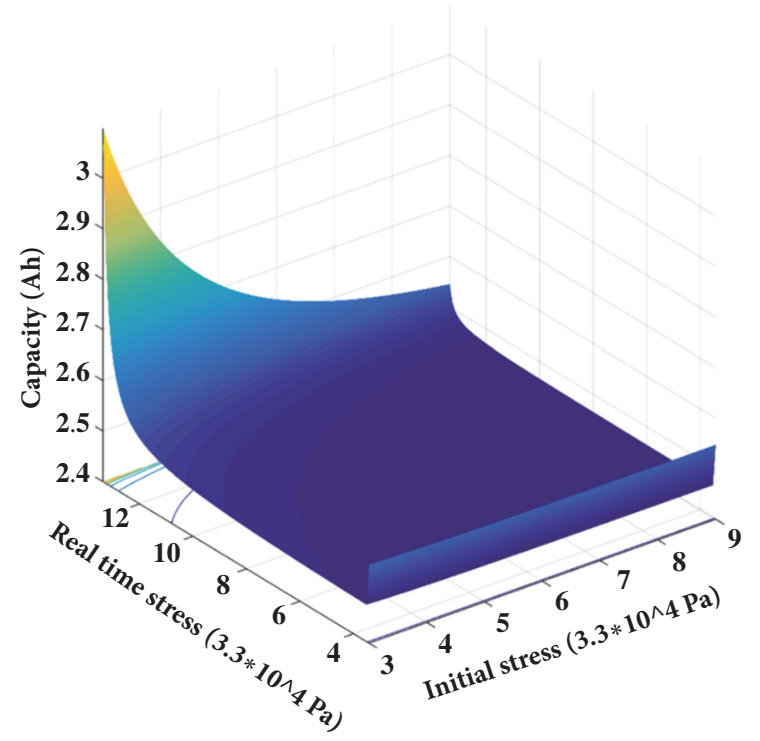

(a)

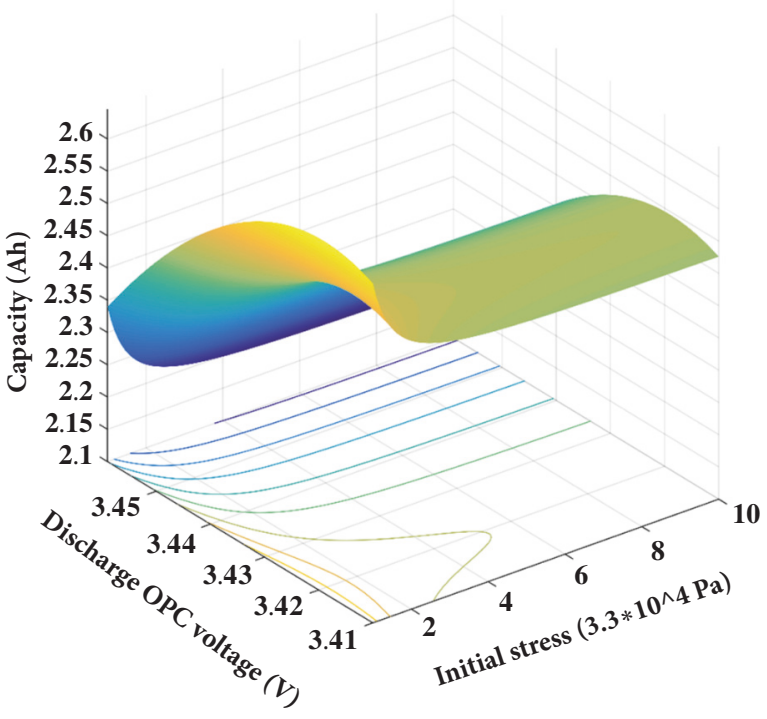

(b)

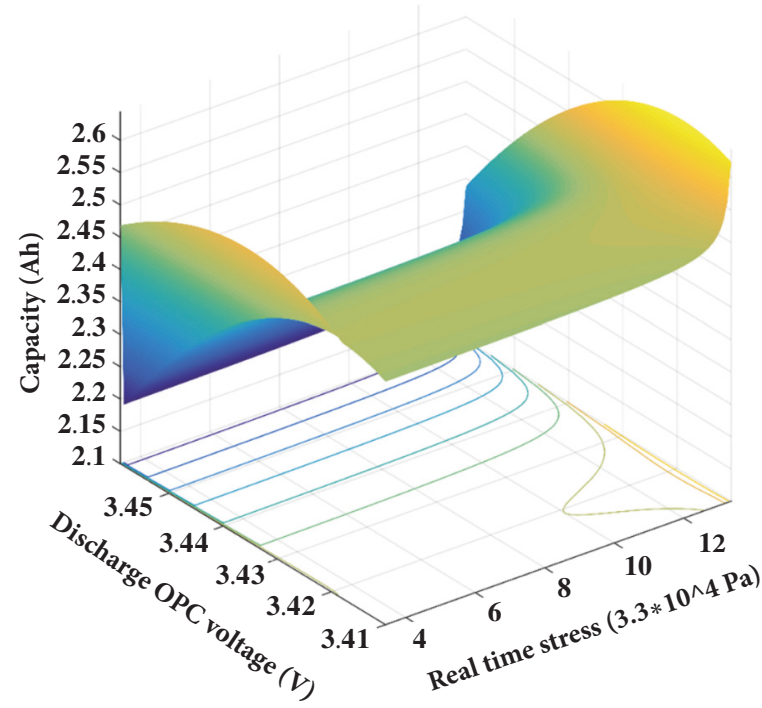

(c)

FIGURE 6: The influence of random double input parameters (initial stress and real-time stress (a); initial stress and discharge OPC voltage (b); real-time stress and discharge OPC voltage (c)) on predicted capacity based on GP model.

be ignored. In Figure 5(c), the cell capacity slightly increases with discharge open circuit voltage before $3.42 \mathrm{~V}$ and keep on decreasing afterwards.

The same experiment protocol was used for 3D plots. For 3D figures, there are two input parameters and one output. The relationship between independent variable and dependent variable is also determined by the GP model. Thus, 3D plots are performed to study the interaction effect of design variables on the capacity of battery. In this interaction analysis, two of the inputs are varied while the other is kept constant at its mean values. These results are in good consistency with that of the parametric analysis. In Figure 6(a), similar effects are observed for initial stress and real-time stress on the capacity. It is noteworthy that the capacity surges drastically at low initial stress and high real-time stress conditions. In Figure 6(b), the same conclusion can be drawn on discharge open circuit voltage as mentioned in parametric analysis. It is interesting to point out that the declining trend of capacity at the low range of initial stress is smoother when the value of discharge open circuit voltage is lower instead of high. Similarly, the capacity goes up slower at the high range of real-time stress when the discharge open circuit voltage is at low level, as shown in Figure 6(c).

\section{Conclusions}

In this study, the experimental combined numerical approach for evaluation of battery capacity based on the initial applied 
TABLE 2

\begin{tabular}{|c|c|c|c|c|c|}
\hline load applied (kg) & stress measured (kg) & $\begin{array}{c}\text { discharge OPC } \\
\text { voltage }(\mathrm{V}) \\
\end{array}$ & charge OPC voltage & capacity (Ah) & cycle (n) \\
\hline 3 & 5.175 & 3.433 & 4.173 & 2.475 & 1 \\
\hline 3 & 5.233 & 3.437 & 4.172 & 2.478 & 2 \\
\hline 3 & 5.283 & 3.430 & 4.176 & 2.480 & 3 \\
\hline 3 & 5.312 & 3.435 & 4.177 & 2.477 & 4 \\
\hline 3 & 5.358 & 3.434 & 4.175 & 2.468 & 5 \\
\hline 3 & 5.399 & 3.431 & 4.174 & 2.501 & 6 \\
\hline 3 & 5.416 & 3.434 & 4.175 & 2.489 & 7 \\
\hline 3 & 5.358 & 3.433 & 4.170 & 2.480 & 8 \\
\hline 3 & 5.399 & 3.441 & 4.171 & 2.473 & 9 \\
\hline 3 & 5.416 & 3.432 & 4.177 & 2.523 & 10 \\
\hline 3 & 5.441 & 3.438 & 4.169 & 2.497 & 11 \\
\hline 3 & 5.482 & 3.440 & 4.182 & 2.487 & 12 \\
\hline 3 & 5.515 & 3.440 & 4.182 & 2.483 & 13 \\
\hline 3 & 5.534 & 3.434 & 4.181 & 2.519 & 14 \\
\hline 3 & 5.552 & 3.431 & 4.182 & 2.506 & 15 \\
\hline 3 & 5.573 & 3.433 & 4.182 & 2.499 & 16 \\
\hline 3 & 5.600 & 3.433 & 4.184 & 2.495 & 17 \\
\hline 3 & 5.617 & 3.428 & 4.184 & 2.523 & 18 \\
\hline 3 & 5.615 & 3.429 & 4.184 & 2.512 & 19 \\
\hline 3 & 5.642 & 3.430 & 4.184 & 2.506 & 20 \\
\hline 3 & 5.660 & 3.431 & 4.184 & 2.502 & 21 \\
\hline 3 & 5.677 & 3.428 & 4.184 & 2.518 & 22 \\
\hline 3 & 5.673 & 3.426 & 4.184 & 2.525 & 23 \\
\hline 3 & 5.695 & 3.428 & 4.185 & 2.517 & 24 \\
\hline 3 & 5.706 & 3.429 & 4.184 & 2.512 & 25 \\
\hline 3 & 5.724 & 3.426 & 4.184 & 2.525 & 26 \\
\hline 3 & 5.704 & 3.422 & 4.184 & 2.542 & 27 \\
\hline 3 & 5.718 & 3.425 & 4.185 & 2.529 & 28 \\
\hline 3 & 5.731 & 3.427 & 4.185 & 2.522 & 29 \\
\hline 3 & 5.751 & 3.427 & 4.185 & 2.519 & 30 \\
\hline 3 & 5.741 & 3.422 & 4.184 & 2.540 & 31 \\
\hline 3 & 5.751 & 3.425 & 4.185 & 2.528 & 32 \\
\hline 3 & 5.749 & 3.426 & 4.185 & 2.520 & 33 \\
\hline 3 & 5.760 & 3.427 & 4.185 & 2.514 & 34 \\
\hline 3 & 5.768 & 3.421 & 4.184 & 2.539 & 35 \\
\hline 3 & 5.758 & 3.423 & 4.185 & 2.530 & 36 \\
\hline 3 & 5.770 & 3.425 & 4.185 & 2.523 & 37 \\
\hline 3 & 5.778 & 3.426 & 4.185 & 2.516 & 38 \\
\hline 3 & 5.793 & 3.422 & 4.184 & 2.535 & 39 \\
\hline 3 & 5.766 & 3.421 & 4.185 & 2.537 & 40 \\
\hline 3 & 5.785 & 3.423 & 4.185 & 2.529 & 41 \\
\hline 3 & 5.797 & 3.424 & 4.185 & 2.523 & 42 \\
\hline 3 & 5.807 & 3.423 & 4.185 & 2.525 & 43 \\
\hline 3 & 5.805 & 3.423 & 4.184 & 2.528 & 44 \\
\hline 3 & 5.811 & 3.424 & 4.185 & 2.524 & 45 \\
\hline 3 & 5.820 & 3.425 & 4.185 & 2.517 & 46 \\
\hline 3 & 5.828 & 3.424 & 4.184 & 2.522 & 47 \\
\hline 3 & 5.824 & 3.415 & 4.184 & 2.548 & 48 \\
\hline 3 & 5.816 & 3.420 & 4.185 & 2.535 & 49 \\
\hline 3 & 5.826 & 3.423 & 4.185 & 2.524 & 50 \\
\hline
\end{tabular}


TABLe 2: Continued.

\begin{tabular}{|c|c|c|c|c|c|}
\hline load applied (kg) & stress measured (kg) & $\begin{array}{c}\text { discharge OPC } \\
\text { voltage }(\mathrm{V}) \\
\end{array}$ & charge OPC voltage & capacity (Ah) & cycle (n) \\
\hline 3 & 5.834 & 3.424 & 4.184 & 2.519 & 51 \\
\hline 3 & 5.836 & 3.416 & 4.184 & 2.544 & 52 \\
\hline 3 & 5.822 & 3.419 & 4.185 & 2.536 & 53 \\
\hline 3 & 5.832 & 3.420 & 4.185 & 2.533 & 54 \\
\hline 3 & 5.838 & 3.423 & 4.185 & 2.523 & 55 \\
\hline 3 & 5.851 & 3.419 & 4.185 & 2.535 & 56 \\
\hline 3 & 5.836 & 3.421 & 4.185 & 2.528 & 57 \\
\hline 3 & 5.849 & 3.424 & 4.185 & 2.516 & 58 \\
\hline 3 & 5.855 & 3.425 & 4.184 & 2.509 & 59 \\
\hline 3 & 5.869 & 3.423 & 4.184 & 2.517 & 60 \\
\hline 3 & 5.853 & 3.420 & 4.184 & 2.528 & 61 \\
\hline 3 & 5.859 & 3.423 & 4.185 & 2.518 & 62 \\
\hline 3 & 5.865 & 3.425 & 4.185 & 2.509 & 63 \\
\hline 3 & 5.869 & 3.425 & 4.185 & 2.509 & 64 \\
\hline 3 & 5.857 & 3.419 & 4.184 & 2.529 & 65 \\
\hline 3 & 5.859 & 3.421 & 4.185 & 2.524 & 66 \\
\hline 3 & 5.863 & 3.422 & 4.185 & 2.519 & 67 \\
\hline 3 & 5.867 & 3.423 & 4.185 & 2.515 & 68 \\
\hline 3 & 5.865 & 3.416 & 4.184 & 2.536 & 69 \\
\hline 3 & 5.849 & 3.417 & 4.185 & 2.534 & 70 \\
\hline 3 & 5.855 & 3.419 & 4.185 & 2.530 & 71 \\
\hline 3 & 5.859 & 3.420 & 4.185 & 2.525 & 72 \\
\hline 3 & 5.874 & 3.420 & 4.185 & 2.525 & 73 \\
\hline 3 & 5.859 & 3.420 & 4.185 & 2.526 & 74 \\
\hline 3 & 5.863 & 3.421 & 4.185 & 2.520 & 75 \\
\hline 3 & 5.867 & 3.421 & 4.185 & 2.519 & 76 \\
\hline 3 & 5.869 & 3.421 & 4.185 & 2.517 & 77 \\
\hline 3 & 5.869 & 3.422 & 4.185 & 2.515 & 78 \\
\hline 3 & 5.863 & 3.421 & 4.186 & 2.517 & 79 \\
\hline 3 & 5.865 & 3.422 & 4.185 & 2.512 & 80 \\
\hline 3 & 5.869 & 3.423 & 4.184 & 2.507 & 81 \\
\hline 3 & 5.874 & 3.423 & 4.184 & 2.505 & 82 \\
\hline 3 & 5.872 & 3.424 & 4.184 & 2.500 & 83 \\
\hline 3 & 5.874 & 3.425 & 4.184 & 2.498 & 84 \\
\hline 3 & 5.878 & 3.426 & 4.184 & 2.495 & 85 \\
\hline 3 & 5.880 & 3.425 & 4.184 & 2.496 & 86 \\
\hline 3 & 5.876 & 3.425 & 4.184 & 2.495 & 87 \\
\hline 3 & 5.878 & 3.426 & 4.184 & 2.494 & 88 \\
\hline 3 & 5.876 & 3.426 & 4.184 & 2.493 & 89 \\
\hline 3 & 5.878 & 3.426 & 4.184 & 2.493 & 90 \\
\hline 3 & 5.872 & 3.426 & 4.184 & 2.488 & 91 \\
\hline 3 & 5.882 & 3.429 & 4.183 & 2.474 & 92 \\
\hline 3 & 5.892 & 3.432 & 4.183 & 2.463 & 93 \\
\hline 3 & 5.898 & 3.433 & 4.183 & 2.453 & 94 \\
\hline 3 & 5.898 & 3.434 & 4.183 & 2.448 & 95 \\
\hline 3 & 5.903 & 3.435 & 4.183 & 2.443 & 96 \\
\hline 3 & 5.911 & 3.436 & 4.183 & 2.437 & 97 \\
\hline 3 & 5.911 & 3.437 & 4.182 & 2.435 & 98 \\
\hline 3 & 5.894 & 3.431 & 4.183 & 2.463 & 99 \\
\hline 3 & 5.894 & 3.433 & 4.183 & 2.451 & 100 \\
\hline
\end{tabular}


TABle 2: Continued.

\begin{tabular}{|c|c|c|c|c|c|}
\hline load applied (kg) & stress measured (kg) & $\begin{array}{c}\text { discharge OPC } \\
\text { voltage }(\mathrm{V}) \\
\end{array}$ & charge OPC voltage & capacity (Ah) & cycle (n) \\
\hline 3 & 5.898 & 3.434 & 4.183 & 2.447 & 101 \\
\hline 3 & 5.903 & 3.435 & 4.183 & 2.440 & 102 \\
\hline 3 & 5.896 & 3.429 & 4.182 & 2.469 & 103 \\
\hline 3 & 5.878 & 3.430 & 4.183 & 2.467 & 104 \\
\hline 3 & 5.890 & 3.432 & 4.183 & 2.456 & 105 \\
\hline 3 & 5.894 & 3.434 & 4.183 & 2.444 & 106 \\
\hline 3 & 5.901 & 3.432 & 4.182 & 2.456 & 107 \\
\hline 3 & 5.880 & 3.429 & 4.183 & 2.467 & 108 \\
\hline 3 & 5.890 & 3.432 & 4.183 & 2.455 & 109 \\
\hline 3 & 5.896 & 3.434 & 4.183 & 2.445 & 110 \\
\hline 3 & 5.903 & 3.434 & 4.183 & 2.445 & 111 \\
\hline 3 & 5.884 & 3.428 & 4.182 & 2.470 & 112 \\
\hline 3 & 5.884 & 3.431 & 4.183 & 2.456 & 113 \\
\hline 3 & 5.892 & 3.433 & 4.183 & 2.449 & 114 \\
\hline 3 & 5.894 & 3.433 & 4.183 & 2.445 & 115 \\
\hline 3 & 5.882 & 3.427 & 4.183 & 2.476 & 116 \\
\hline 3 & 5.874 & 3.429 & 4.183 & 2.465 & 117 \\
\hline 3 & 5.880 & 3.430 & 4.183 & 2.459 & 118 \\
\hline 3 & 5.886 & 3.431 & 4.183 & 2.453 & 119 \\
\hline 6 & 8.105 & 3.437 & 4.178 & 2.539 & 1 \\
\hline 6 & 8.145 & 3.438 & 4.177 & 2.524 & 2 \\
\hline 6 & 8.176 & 3.436 & 4.178 & 2.533 & 3 \\
\hline 6 & 8.184 & 3.434 & 4.178 & 2.532 & 4 \\
\hline 6 & 8.207 & 3.433 & 4.178 & 2.534 & 5 \\
\hline 6 & 8.234 & 3.433 & 4.178 & 2.529 & 6 \\
\hline 6 & 8.240 & 3.430 & 4.179 & 2.547 & 7 \\
\hline 6 & 8.248 & 3.428 & 4.179 & 2.551 & 8 \\
\hline 6 & 8.271 & 3.429 & 4.179 & 2.546 & 9 \\
\hline 6 & 8.290 & 3.429 & 4.179 & 2.540 & 10 \\
\hline 6 & 8.302 & 3.424 & 4.179 & 2.560 & 11 \\
\hline 6 & 8.314 & 3.426 & 4.179 & 2.551 & 12 \\
\hline 6 & 8.327 & 3.427 & 4.179 & 2.543 & 13 \\
\hline 6 & 8.339 & 3.428 & 4.179 & 2.540 & 14 \\
\hline 6 & 8.346 & 3.428 & 4.179 & 2.540 & 15 \\
\hline 6 & 8.352 & 3.428 & 4.179 & 2.539 & 16 \\
\hline 6 & 8.362 & 3.428 & 4.179 & 2.535 & 17 \\
\hline 6 & 8.372 & 3.428 & 4.179 & 2.535 & 18 \\
\hline 6 & 8.375 & 3.425 & 4.179 & 2.543 & 19 \\
\hline 6 & 8.381 & 3.426 & 4.179 & 2.538 & 20 \\
\hline 6 & 8.389 & 3.427 & 4.179 & 2.534 & 21 \\
\hline 6 & 8.395 & 3.426 & 4.179 & 2.538 & 22 \\
\hline 6 & 8.420 & 3.425 & 4.179 & 2.539 & 23 \\
\hline 6 & 8.420 & 3.425 & 4.179 & 2.537 & 24 \\
\hline 6 & 8.424 & 3.426 & 4.179 & 2.537 & 25 \\
\hline 6 & 8.437 & 3.427 & 4.179 & 2.533 & 26 \\
\hline 6 & 8.468 & 3.432 & 4.179 & 2.507 & 27 \\
\hline 6 & 8.476 & 3.433 & 4.179 & 2.501 & 28 \\
\hline 6 & 8.482 & 3.434 & 4.179 & 2.494 & 29 \\
\hline 6 & 8.484 & 3.436 & 4.178 & 2.482 & 30 \\
\hline 6 & 8.491 & 3.439 & 4.178 & 2.472 & 31 \\
\hline
\end{tabular}


TABle 2: Continued.

\begin{tabular}{|c|c|c|c|c|c|}
\hline load applied (kg) & stress measured (kg) & $\begin{array}{c}\text { discharge OPC } \\
\text { voltage }(\mathrm{V})\end{array}$ & charge OPC voltage & capacity (Ah) & cycle (n) \\
\hline 6 & 8.493 & 3.440 & 4.178 & 2.463 & 32 \\
\hline 6 & 8.493 & 3.442 & 4.177 & 2.451 & 33 \\
\hline 6 & 8.484 & 3.441 & 4.178 & 2.457 & 34 \\
\hline 6 & 8.491 & 3.440 & 4.178 & 2.458 & 35 \\
\hline 6 & 8.493 & 3.441 & 4.177 & 2.453 & 36 \\
\hline 6 & 8.493 & 3.441 & 4.178 & 2.449 & 37 \\
\hline 6 & 8.484 & 3.434 & 4.178 & 2.485 & 38 \\
\hline 6 & 8.488 & 3.436 & 4.178 & 2.478 & 39 \\
\hline 6 & 8.497 & 3.437 & 4.178 & 2.470 & 40 \\
\hline 6 & 8.488 & 3.437 & 4.178 & 2.470 & 41 \\
\hline 6 & 8.497 & 3.431 & 4.179 & 2.503 & 42 \\
\hline 6 & 8.493 & 3.434 & 4.178 & 2.483 & 43 \\
\hline 6 & 8.486 & 3.437 & 4.178 & 2.473 & 44 \\
\hline 6 & 8.497 & 3.435 & 4.178 & 2.480 & 45 \\
\hline 6 & 8.503 & 3.435 & 4.179 & 2.482 & 46 \\
\hline 6 & 8.499 & 3.431 & 4.181 & 2.481 & 47 \\
\hline 6 & 8.509 & 3.432 & 4.180 & 2.472 & 48 \\
\hline 6 & 8.513 & 3.432 & 4.180 & 2.474 & 49 \\
\hline 6 & 8.515 & 3.430 & 4.181 & 2.482 & 50 \\
\hline 6 & 8.513 & 3.432 & 4.180 & 2.469 & 51 \\
\hline 6 & 8.520 & 3.433 & 4.180 & 2.465 & 52 \\
\hline 6 & 8.522 & 3.431 & 4.180 & 2.475 & 53 \\
\hline 6 & 8.528 & 3.425 & 4.181 & 2.503 & 54 \\
\hline 6 & 8.526 & 3.428 & 4.181 & 2.491 & 55 \\
\hline 6 & 8.520 & 3.429 & 4.181 & 2.485 & 56 \\
\hline 6 & 8.520 & 3.428 & 4.181 & 2.489 & 57 \\
\hline 6 & 8.528 & 3.421 & 4.182 & 2.516 & 58 \\
\hline 6 & 8.511 & 3.425 & 4.181 & 2.500 & 59 \\
\hline 6 & 8.513 & 3.426 & 4.181 & 2.494 & 60 \\
\hline 6 & 8.513 & 3.428 & 4.181 & 2.488 & 61 \\
\hline 6 & 8.522 & 3.422 & 4.181 & 2.510 & 62 \\
\hline 6 & 8.517 & 3.426 & 4.181 & 2.493 & 63 \\
\hline 6 & 8.507 & 3.428 & 4.181 & 2.485 & 64 \\
\hline 6 & 8.513 & 3.429 & 4.180 & 2.480 & 65 \\
\hline 6 & 8.517 & 3.422 & 4.181 & 2.506 & 66 \\
\hline 6 & 8.522 & 3.425 & 4.181 & 2.494 & 67 \\
\hline 6 & 8.513 & 3.427 & 4.181 & 2.490 & 68 \\
\hline 6 & 8.513 & 3.428 & 4.181 & 2.482 & 69 \\
\hline 6 & 8.517 & 3.421 & 4.181 & 2.507 & 70 \\
\hline 6 & 8.520 & 3.424 & 4.181 & 2.497 & 71 \\
\hline 6 & 8.501 & 3.425 & 4.181 & 2.492 & 72 \\
\hline 6 & 8.507 & 3.426 & 4.181 & 2.487 & 73 \\
\hline 6 & 8.509 & 3.425 & 4.181 & 2.494 & 74 \\
\hline 6 & 8.513 & 3.425 & 4.181 & 2.491 & 75 \\
\hline 6 & 8.507 & 3.426 & 4.181 & 2.489 & 76 \\
\hline 6 & 8.503 & 3.428 & 4.181 & 2.482 & 77 \\
\hline 6 & 8.505 & 3.422 & 4.181 & 2.503 & 78 \\
\hline 6 & 8.513 & 3.422 & 4.181 & 2.500 & 79 \\
\hline 6 & 8.482 & 3.425 & 4.181 & 2.489 & 80 \\
\hline 6 & 8.486 & 3.427 & 4.180 & 2.481 & 81 \\
\hline
\end{tabular}


TABLe 2: Continued.

\begin{tabular}{|c|c|c|c|c|c|}
\hline load applied (kg) & stress measured (kg) & $\begin{array}{c}\text { discharge } \mathrm{OPC} \\
\text { voltage }(\mathrm{V})\end{array}$ & charge OPC voltage & capacity (Ah) & cycle $(n)$ \\
\hline 6 & 8.493 & 3.422 & 4.180 & 2.499 & 82 \\
\hline 6 & 8.499 & 3.422 & 4.181 & 2.502 & 83 \\
\hline 6 & 8.470 & 3.424 & 4.181 & 2.494 & 84 \\
\hline 6 & 8.480 & 3.426 & 4.181 & 2.484 & 85 \\
\hline 6 & 8.476 & 3.423 & 4.180 & 2.492 & 86 \\
\hline 6 & 8.493 & 3.423 & 4.181 & 2.494 & 87 \\
\hline 6 & 8.470 & 3.426 & 4.180 & 2.480 & 88 \\
\hline 6 & 8.476 & 3.428 & 4.180 & 2.474 & 89 \\
\hline 6 & 8.484 & 3.426 & 4.180 & 2.481 & 90 \\
\hline 6 & 8.491 & 3.424 & 4.180 & 2.490 & 91 \\
\hline 6 & 8.466 & 3.426 & 4.180 & 2.479 & 92 \\
\hline 6 & 8.472 & 3.428 & 4.180 & 2.471 & 93 \\
\hline 6 & 8.476 & 3.426 & 4.180 & 2.480 & 94 \\
\hline 6 & 8.486 & 3.424 & 4.181 & 2.490 & 95 \\
\hline 6 & 8.462 & 3.425 & 4.180 & 2.485 & 96 \\
\hline 6 & 8.464 & 3.426 & 4.181 & 2.481 & 97 \\
\hline 6 & 8.464 & 3.426 & 4.180 & 2.478 & 98 \\
\hline 6 & 8.462 & 3.419 & 4.181 & 2.501 & 99 \\
\hline 6 & 8.462 & 3.422 & 4.181 & 2.492 & 100 \\
\hline 6 & 8.441 & 3.423 & 4.180 & 2.488 & 101 \\
\hline 6 & 8.443 & 3.424 & 4.180 & 2.484 & 102 \\
\hline 6 & 8.445 & 3.424 & 4.181 & 2.484 & 103 \\
\hline 6 & 8.457 & 3.423 & 4.181 & 2.487 & 104 \\
\hline 6 & 8.439 & 3.424 & 4.180 & 2.483 & 105 \\
\hline 6 & 8.439 & 3.424 & 4.180 & 2.481 & 106 \\
\hline 6 & 8.439 & 3.425 & 4.180 & 2.478 & 107 \\
\hline 6 & 8.449 & 3.423 & 4.181 & 2.485 & 108 \\
\hline 6 & 8.362 & 3.424 & 4.181 & 2.483 & 109 \\
\hline 6 & 8.358 & 3.425 & 4.180 & 2.477 & 110 \\
\hline 6 & 8.358 & 3.425 & 4.180 & 2.473 & 111 \\
\hline 6 & 8.358 & 3.426 & 4.181 & 2.470 & 112 \\
\hline 6 & 8.360 & 3.427 & 4.180 & 2.467 & 113 \\
\hline 6 & 8.360 & 3.427 & 4.180 & 2.463 & 114 \\
\hline 6 & 8.362 & 3.427 & 4.180 & 2.466 & 115 \\
\hline 6 & 8.360 & 3.427 & 4.180 & 2.465 & 116 \\
\hline 6 & 8.358 & 3.427 & 4.180 & 2.464 & 117 \\
\hline 6 & 8.358 & 3.428 & 4.180 & 2.463 & 118 \\
\hline 6 & 8.356 & 3.428 & 4.180 & 2.462 & 119 \\
\hline 6 & 8.354 & 3.428 & 4.180 & 2.459 & 120 \\
\hline 6 & 8.348 & 3.431 & 4.180 & 2.442 & 121 \\
\hline 6 & 8.358 & 3.433 & 4.179 & 2.431 & 122 \\
\hline 6 & 8.366 & 3.435 & 4.179 & 2.420 & 123 \\
\hline 6 & 8.375 & 3.436 & 4.180 & 2.419 & 124 \\
\hline 6 & 8.375 & 3.437 & 4.179 & 2.408 & 125 \\
\hline 6 & 8.381 & 3.438 & 4.179 & 2.403 & 126 \\
\hline 6 & 8.383 & 3.437 & 4.178 & 2.410 & 127 \\
\hline 6 & 8.387 & 3.433 & 4.179 & 2.424 & 128 \\
\hline 6 & 8.366 & 3.435 & 4.179 & 2.417 & 129 \\
\hline 6 & 8.372 & 3.436 & 4.178 & 2.410 & 130 \\
\hline
\end{tabular}


TABLE 2: Continued.

\begin{tabular}{|c|c|c|c|c|c|}
\hline load applied (kg) & stress measured (kg) & $\begin{array}{c}\text { discharge OPC } \\
\text { voltage }(\mathrm{V}) \\
\end{array}$ & charge OPC voltage & capacity (Ah) & cycle (n) \\
\hline 6 & 8.375 & 3.436 & 4.178 & 2.412 & 131 \\
\hline 6 & 8.377 & 3.430 & 4.179 & 2.442 & 132 \\
\hline 6 & 8.358 & 3.433 & 4.179 & 2.427 & 133 \\
\hline 6 & 8.366 & 3.434 & 4.179 & 2.418 & 134 \\
\hline 6 & 8.368 & 3.436 & 4.179 & 2.411 & 135 \\
\hline 6 & 8.358 & 3.430 & 4.179 & 2.437 & 136 \\
\hline 6 & 8.354 & 3.433 & 4.179 & 2.427 & 137 \\
\hline 6 & 8.362 & 3.435 & 4.179 & 2.416 & 138 \\
\hline 6 & 8.370 & 3.437 & 4.179 & 2.405 & 139 \\
\hline 6 & 8.360 & 3.431 & 4.179 & 2.432 & 140 \\
\hline 6 & 8.348 & 3.432 & 4.179 & 2.427 & 141 \\
\hline 6 & 8.354 & 3.434 & 4.179 & 2.419 & 142 \\
\hline 6 & 8.358 & 3.436 & 4.179 & 2.411 & 143 \\
\hline 6 & 8.356 & 3.430 & 4.180 & 2.437 & 144 \\
\hline 6 & 8.337 & 3.430 & 4.180 & 2.436 & 145 \\
\hline 6 & 8.346 & 3.431 & 4.179 & 2.430 & 146 \\
\hline 6 & 8.352 & 3.433 & 4.180 & 2.423 & 147 \\
\hline 6 & 8.312 & 3.429 & 4.179 & 2.441 & 148 \\
\hline 9 & 10.608 & 3.439 & 4.178 & 2.548 & 1 \\
\hline 9 & 10.608 & 3.439 & 4.178 & 2.534 & 2 \\
\hline 9 & 10.691 & 3.437 & 4.178 & 2.544 & 3 \\
\hline 9 & 10.755 & 3.436 & 4.179 & 2.541 & 4 \\
\hline 9 & 10.770 & 3.434 & 4.178 & 2.546 & 5 \\
\hline 9 & 10.761 & 3.434 & 4.178 & 2.542 & 6 \\
\hline 9 & 10.691 & 3.429 & 4.179 & 2.566 & 7 \\
\hline 9 & 10.755 & 3.428 & 4.180 & 2.570 & 8 \\
\hline 9 & 10.770 & 3.428 & 4.180 & 2.567 & 9 \\
\hline 9 & 10.803 & 3.429 & 4.179 & 2.562 & 10 \\
\hline 9 & 10.822 & 3.424 & 4.180 & 2.580 & 11 \\
\hline 9 & 10.830 & 3.425 & 4.180 & 2.571 & 12 \\
\hline 9 & 10.834 & 3.426 & 4.180 & 2.566 & 13 \\
\hline 9 & 10.803 & 3.427 & 4.179 & 2.562 & 14 \\
\hline 9 & 10.822 & 3.427 & 4.179 & 2.562 & 15 \\
\hline 9 & 10.830 & 3.427 & 4.179 & 2.560 & 16 \\
\hline 9 & 10.834 & 3.428 & 4.180 & 2.559 & 17 \\
\hline 9 & 10.832 & 3.427 & 4.179 & 2.559 & 18 \\
\hline 9 & 10.844 & 3.425 & 4.180 & 2.565 & 19 \\
\hline 9 & 10.834 & 3.426 & 4.179 & 2.561 & 20 \\
\hline 9 & 10.840 & 3.426 & 4.180 & 2.560 & 21 \\
\hline 9 & 10.846 & 3.424 & 4.180 & 2.566 & 22 \\
\hline 9 & 10.853 & 3.424 & 4.180 & 2.564 & 23 \\
\hline 9 & 10.855 & 3.425 & 4.180 & 2.562 & 24 \\
\hline 9 & 10.838 & 3.425 & 4.180 & 2.561 & 25 \\
\hline 9 & 10.824 & 3.429 & 4.180 & 2.547 & 26 \\
\hline 9 & 10.853 & 3.430 & 4.179 & 2.539 & 27 \\
\hline
\end{tabular}


TABle 2: Continued.

\begin{tabular}{|c|c|c|c|c|c|}
\hline load applied (kg) & stress measured (kg) & $\begin{array}{c}\text { discharge OPC } \\
\text { voltage }(\mathrm{V})\end{array}$ & charge OPC voltage & capacity (Ah) & cycle (n) \\
\hline 9 & 10.855 & 3.432 & 4.179 & 2.530 & 28 \\
\hline 9 & 10.838 & 3.433 & 4.179 & 2.522 & 29 \\
\hline 9 & 10.836 & 3.435 & 4.179 & 2.510 & 30 \\
\hline 9 & 10.838 & 3.437 & 4.199 & 2.505 & 31 \\
\hline 9 & 10.832 & 3.438 & 4.178 & 2.497 & 32 \\
\hline 9 & 10.824 & 3.440 & 4.178 & 2.485 & 33 \\
\hline 9 & 10.836 & 3.439 & 4.178 & 2.487 & 34 \\
\hline 9 & 10.838 & 3.439 & 4.178 & 2.484 & 35 \\
\hline 9 & 10.832 & 3.440 & 4.178 & 2.479 & 36 \\
\hline 9 & 10.824 & 3.441 & 4.177 & 2.475 & 37 \\
\hline 9 & 10.822 & 3.433 & 4.178 & 2.515 & 38 \\
\hline 9 & 10.817 & 3.434 & 4.178 & 2.508 & 39 \\
\hline 9 & 10.766 & 3.436 & 4.178 & 2.502 & 40 \\
\hline 9 & 10.778 & 3.434 & 4.178 & 2.509 & 41 \\
\hline 9 & 10.822 & 3.430 & 4.178 & 2.529 & 42 \\
\hline 9 & 10.817 & 3.433 & 4.179 & 2.513 & 43 \\
\hline 9 & 10.766 & 3.436 & 4.179 & 2.502 & 44 \\
\hline 9 & 10.778 & 3.433 & 4.178 & 2.516 & 45 \\
\hline 9 & 10.770 & 3.431 & 4.179 & 2.508 & 46 \\
\hline 9 & 10.774 & 3.430 & 4.179 & 2.509 & 47 \\
\hline 9 & 10.813 & 3.431 & 4.181 & 2.503 & 48 \\
\hline 9 & 10.803 & 3.428 & 4.181 & 2.519 & 49 \\
\hline 9 & 10.807 & 3.429 & 4.181 & 2.514 & 50 \\
\hline 9 & 10.805 & 3.431 & 4.181 & 2.507 & 51 \\
\hline 9 & 10.811 & 3.431 & 4.181 & 2.503 & 52 \\
\hline 9 & 10.803 & 3.427 & 4.181 & 2.521 & 53 \\
\hline 9 & 10.784 & 3.424 & 4.181 & 2.532 & 54 \\
\hline 9 & 10.805 & 3.426 & 4.182 & 2.524 & 55 \\
\hline 9 & 10.811 & 3.428 & 4.181 & 2.517 & 56 \\
\hline 9 & 10.803 & 3.421 & 4.181 & 2.540 & 57 \\
\hline 9 & 10.784 & 3.421 & 4.181 & 2.543 & 58 \\
\hline 9 & 10.790 & 3.423 & 4.182 & 2.534 & 59 \\
\hline 9 & 10.759 & 3.425 & 4.181 & 2.523 & 60 \\
\hline 9 & 10.784 & 3.422 & 4.181 & 2.536 & 61 \\
\hline 9 & 10.790 & 3.422 & 4.181 & 2.535 & 62 \\
\hline 9 & 10.759 & 3.427 & 4.181 & 2.519 & 63 \\
\hline 9 & 10.764 & 3.429 & 4.181 & 2.509 & 64 \\
\hline 9 & 10.772 & 3.424 & 4.181 & 2.527 & 65 \\
\hline 9 & 10.768 & 3.424 & 4.181 & 2.527 & 66 \\
\hline 9 & 10.745 & 3.426 & 4.181 & 2.519 & 67 \\
\hline 9 & 10.730 & 3.428 & 4.181 & 2.511 & 68 \\
\hline 9 & 10.735 & 3.424 & 4.181 & 2.527 & 69 \\
\hline 9 & 10.749 & 3.423 & 4.181 & 2.530 & 70 \\
\hline 9 & 10.716 & 3.425 & 4.181 & 2.524 & 71 \\
\hline 9 & 10.726 & 3.426 & 4.182 & 2.517 & 72 \\
\hline 9 & 10.732 & 3.425 & 4.181 & 2.519 & 73 \\
\hline 9 & 10.712 & 3.425 & 4.181 & 2.520 & 74 \\
\hline 9 & 10.710 & 3.425 & 4.181 & 2.517 & 75 \\
\hline
\end{tabular}


TABLE 2: Continued.

\begin{tabular}{|c|c|c|c|c|c|}
\hline load applied (kg) & stress measured (kg) & $\begin{array}{c}\text { discharge OPC } \\
\text { voltage }(\mathrm{V})\end{array}$ & charge OPC voltage & capacity (Ah) & cycle (n) \\
\hline 9 & 10.703 & 3.427 & 4.181 & 2.510 & 76 \\
\hline 9 & 10.708 & 3.423 & 4.181 & 2.523 & 77 \\
\hline 9 & 10.679 & 3.422 & 4.181 & 2.530 & 78 \\
\hline 9 & 10.672 & 3.425 & 4.181 & 2.517 & 79 \\
\hline 9 & 10.674 & 3.427 & 4.181 & 2.510 & 80 \\
\hline 9 & 10.691 & 3.423 & 4.181 & 2.523 & 81 \\
\hline 9 & 10.662 & 3.421 & 4.181 & 2.529 & 82 \\
\hline 9 & 10.674 & 3.423 & 4.181 & 2.520 & 83 \\
\hline 9 & 10.677 & 3.426 & 4.181 & 2.510 & 84 \\
\hline 9 & 10.687 & 3.423 & 4.181 & 2.519 & 85 \\
\hline 9 & 10.654 & 3.423 & 4.181 & 2.519 & 86 \\
\hline 9 & 10.660 & 3.426 & 4.181 & 2.506 & 87 \\
\hline 9 & 10.662 & 3.429 & 4.180 & 2.498 & 88 \\
\hline 9 & 10.679 & 3.425 & 4.181 & 2.508 & 89 \\
\hline 9 & 10.631 & 3.424 & 4.181 & 2.514 & 90 \\
\hline 9 & 10.654 & 3.426 & 4.181 & 2.503 & 91 \\
\hline 9 & 10.645 & 3.428 & 4.180 & 2.495 & 92 \\
\hline 9 & 10.664 & 3.425 & 4.181 & 2.507 & 93 \\
\hline 9 & 10.645 & 3.423 & 4.181 & 2.513 & 94 \\
\hline 9 & 10.641 & 3.424 & 4.181 & 2.508 & 95 \\
\hline 9 & 10.658 & 3.426 & 4.181 & 2.504 & 96 \\
\hline 9 & 10.610 & 3.425 & 4.181 & 2.505 & 97 \\
\hline 9 & 10.621 & 3.420 & 4.181 & 2.525 & 98 \\
\hline 9 & 10.627 & 3.422 & 4.181 & 2.517 & 99 \\
\hline 9 & 10.641 & 3.423 & 4.181 & 2.512 & 100 \\
\hline 9 & 10.610 & 3.424 & 4.181 & 2.511 & 101 \\
\hline 9 & 10.623 & 3.421 & 4.181 & 2.517 & 102 \\
\hline 9 & 10.612 & 3.421 & 4.181 & 2.516 & 103 \\
\hline 9 & 10.631 & 3.422 & 4.181 & 2.513 & 104 \\
\hline 9 & 10.612 & 3.422 & 4.181 & 2.513 & 105 \\
\hline 9 & 10.610 & 3.423 & 4.181 & 2.509 & 106 \\
\hline 9 & 10.616 & 3.422 & 4.181 & 2.511 & 107 \\
\hline 9 & 10.631 & 3.424 & 4.181 & 2.507 & 108 \\
\hline 9 & 10.602 & 3.424 & 4.181 & 2.503 & 109 \\
\hline 9 & 10.612 & 3.425 & 4.181 & 2.501 & 110 \\
\hline 9 & 10.614 & 3.425 & 4.181 & 2.498 & 111 \\
\hline 9 & 10.629 & 3.426 & 4.181 & 2.493 & 112 \\
\hline 9 & 10.600 & 3.427 & 4.180 & 2.491 & 113 \\
\hline 9 & 10.602 & 3.426 & 4.180 & 2.491 & 114 \\
\hline 9 & 10.569 & 3.426 & 4.180 & 2.491 & 115 \\
\hline 9 & 10.571 & 3.427 & 4.180 & 2.489 & 116 \\
\hline 9 & 10.575 & 3.427 & 4.181 & 2.489 & 117 \\
\hline 9 & 10.573 & 3.426 & 4.181 & 2.492 & 118 \\
\hline 9 & 10.577 & 3.430 & 4.181 & 2.474 & 119 \\
\hline 9 & 10.575 & 3.432 & 4.180 & 2.462 & 120 \\
\hline 9 & 10.571 & 3.434 & 4.180 & 2.452 & 121 \\
\hline 9 & 10.569 & 3.435 & 4.180 & 2.446 & 122 \\
\hline 9 & 10.567 & 3.436 & 4.179 & 2.440 & 123 \\
\hline 9 & 10.569 & 3.437 & 4.179 & 2.433 & 124 \\
\hline 9 & 10.579 & 3.438 & 4.179 & 2.426 & 125 \\
\hline
\end{tabular}


TABLE 2: Continued.

\begin{tabular}{|c|c|c|c|c|c|}
\hline load applied (kg) & stress measured (kg) & $\begin{array}{c}\text { discharge OPC } \\
\text { voltage }(V)\end{array}$ & charge OPC voltage & capacity (Ah) & cycle (n) \\
\hline 9 & 10.583 & 3.432 & 4.179 & 2.457 & 126 \\
\hline 9 & 10.589 & 3.434 & 4.180 & 2.443 & 127 \\
\hline 9 & 10.592 & 3.435 & 4.179 & 2.440 & 128 \\
\hline 9 & 10.594 & 3.437 & 4.179 & 2.433 & 129 \\
\hline 9 & 10.587 & 3.430 & 4.179 & 2.465 & 130 \\
\hline 9 & 10.583 & 3.432 & 4.180 & 2.455 & 131 \\
\hline 9 & 10.567 & 3.434 & 4.180 & 2.445 & 132 \\
\hline 9 & 10.575 & 3.436 & 4.180 & 2.436 & 133 \\
\hline 9 & 10.583 & 3.431 & 4.180 & 2.459 & 134 \\
\hline 9 & 10.577 & 3.432 & 4.180 & 2.453 & 135 \\
\hline 9 & 10.569 & 3.434 & 4.180 & 2.443 & 136 \\
\hline 9 & 10.575 & 3.436 & 4.180 & 2.432 & 137 \\
\hline 9 & 10.579 & 3.432 & 4.179 & 2.454 & 138 \\
\hline 9 & 10.563 & 3.432 & 4.180 & 2.454 & 139 \\
\hline 9 & 10.571 & 3.433 & 4.180 & 2.446 & 140 \\
\hline 9 & 10.573 & 3.435 & 4.180 & 2.437 & 141 \\
\hline 9 & 10.575 & 3.430 & 4.179 & 2.459 & 142 \\
\hline 9 & 10.558 & 3.429 & 4.180 & 2.463 & 143 \\
\hline 9 & 10.563 & 3.431 & 4.180 & 2.456 & 144 \\
\hline 9 & 10.569 & 3.432 & 4.180 & 2.449 & 145 \\
\hline 9 & 10.552 & 3.428 & 4.180 & 2.466 & 146 \\
\hline
\end{tabular}

stress, the real-time stress, charging open circuit voltage, and discharging open circuit voltage is proposed. Experiments were designed to validate the robustness of the models, formulated using an evolutionary approach of genetic programming. The accuracy of the proposed GP model is fairly high while the maximum percentage of error is about $5 \%$. Several conclusions and future work, from this study, can be drawn as follows:

(i) Genetic programming (GP) shows a satisfactory performance for prediction of capacity under different applied stresses

(ii) The design variable, open circuit voltage is proved to be irrelevant in evaluation and prediction of battery capacity

(iii) A negative correlation exists between the initial stress and battery capacity while the capacity increases with real-time stress

(iv) The interaction analysis (3D plots) gives a detailed insights of effects of each independent variable on the capacity

\section{Appendix}

See Table 2.

\section{Data Availability}

Authors have included experimental data used in this paper in Table 2.

\section{Conflicts of Interest}

The authors declare that they have no conflicts of interest.

\section{Acknowledgments}

Authors acknowledge Grant DMETKF2018019 by State Key Lab of Digital Manufacturing Equipment \& Technology (Huazhong University of Science and Technology). Authors also like to acknowledge Guangdong University Youth Innovation Talent Project (2016KQNCX053) supported by Department of Education of Guangdong Province.

\section{References}

[1] M. Dubarry, V. Svoboda, R. Hwu, and B. Y. Liaw, "Incremental capacity analysis and close-to-equilibrium OCV measurements to quantify capacity fade in commercial rechargeable lithium batteries," Electrochemical and Solid-State Letters, vol. 9, no. 10, pp. A454-A457, 2006.

[2] M. Ecker, J. B. Gerschler, J. Vogel et al., "Development of a lifetime prediction model for lithium-ion batteries based on extended accelerated aging test data," Journal of Power Sources, vol. 215, pp. 248-257, 2012.

[3] Y. Cai, L. Yang, Z. Deng, X. Zhao, and H. Deng, "Online identification of lithium-ion battery state-of-health based on fast wavelet transform and cross D-Markov machine," Energy, vol. 147, pp. 621-635, 2018.

[4] C. Hu, B. D. Youn, and J. Chung, "A multiscale framework with extended Kalman filter for lithium-ion battery SOC and capacity estimation," Applied Energy, vol. 92, pp. 694-704, 2012. 
[5] S.-C. Huang, K.-H. Tseng, J.-W. Liang, C.-L. Chang, and M. G. Pecht, "An online SOC and SOH estimation model for lithiumion batteries," Energies, vol. 10, no. 4, 2017.

[6] Z. Chen, C. C. Mi, Y. Fu, J. Xu, and X. Gong, "Online battery state of health estimation based on genetic algorithm for electric and hybrid vehicle applications," Journal of Power Sources, vol. 240, pp. 184-192, 2013.

[7] A. Marongiu, T. Pavanarit, and D. U. Sauer, "Influence of current and temperature variation on a $\mathrm{LiFePO} 4$ battery total capacity," in Proceedings of the 27th World Electric Vehicle Symposium and Exhibition, EVS 2014, Spain, November 2013.

[8] M. Galeotti, L. Cinà, C. Giammanco, S. Cordiner, and A. Di Carlo, "Performance analysis and $\mathrm{SOH}$ (state of health) evaluation of lithium polymer batteries through electrochemical impedance spectroscopy," Energy, vol. 89, pp. 678-686, 2015.

[9] V. Ramadesigan, P. W. C. Northrop, S. De, S. Santhanagopalan, R. D. Braatz, and V. R. Subramanian, "Modeling and simulation of lithium-ion batteries from a systems engineering perspective," Journal of The Electrochemical Society, vol. 159, no. 3, pp. R31-R45, 2012.

[10] J. Xu, B. Liu, L. Wang, and S. Shang, "Dynamic mechanical integrity of cylindrical lithium-ion battery cell upon crushing," Engineering Failure Analysis, vol. 53, pp. 97-110, 2015.

[11] J. Xu, B. Liu, X. Wang, and D. Hu, "Computational model of 18650 lithium-ion battery with coupled strain rate and SOC dependencies," Applied Energy, vol. 172, pp. 180-189, 2016.

[12] G. Kermani and E. Sahraei, "Review: Characterization and modeling of the mechanical properties of lithium-ion batteries," Energies, vol. 10, no. 11, 2017.

[13] A. Rajan, V. Vijayaraghavan, M. P. Ooi, A. Garg, and Y. C. Kuang, "A simulation-based probabilistic framework for lithiumion battery modelling," Measurement, vol. 115, pp. 87-94, 2018.

[14] T. Kisters, E. Sahraei, and T. Wierzbicki, "Dynamic impact tests on lithium-ion cells," International Journal of Impact Engineering, vol. 108, pp. 205-216, 2017.

[15] V. Vijayaraghavan, A. Garg, and L. Gao, "Fracture mechanics modelling of lithium-ion batteries under pinch torsion test," Measurement, vol. 114, pp. 382-389, 2018.

[16] C. Sangrós Giménez, B. Finke, C. Nowak, C. Schilde, and A. Kwade, "Structural and mechanical characterization of lithiumion battery electrodes via DEM simulations," Advanced Powder Technology, vol. 29, no. 10, pp. 2312-2321, 2018.

[17] B. Mao, H. Chen, Z. Cui, T. Wu, and Q. Wang, "Failure mechanism of the lithium ion battery during nail penetration," International Journal of Heat and Mass Transfer, vol. 122, pp. 11031115, 2018.

[18] M. F. Lagadec, R. Zahn, and V. Wood, "Designing Polyolefin Separators to Minimize the Impact of Local Compressive Stresses on Lithium Ion Battery Performance," Journal of The Electrochemical Society, vol. 165, no. 9, pp. A1829-A1836, 2018.

[19] J. Xu, L. Wang, J. Guan, and S. Yin, "Coupled effect of strain rate and solvent on dynamic mechanical behaviors of separators in lithium ion batteries," Materials \& Design, vol. 95, pp. 319-328, 2016.

[20] J. Cannarella and C. B. Arnold, "Stress evolution and capacity fade in constrained lithium-ion pouch cells," Journal of Power Sources, vol. 245, pp. 745-751, 2014.

[21] J. Cannarella and C. B. Arnold, "State of health and charge measurements in lithium-ion batteries using mechanical stress," Journal of Power Sources, vol. 269, pp. 7-14, 2014.
[22] A. Garg, X. Peng, M. L. Le, K. Pareek, and C. Chin, "Design and analysis of capacity models for Lithium-ion battery," Measurement, vol. 120, pp. 114-120, 2018.

[23] K. Abhishek, B. N. Panda, S. Datta, and S. S. Mahapatra, "Comparing Predictability of Genetic Programming and ANFIS on Drilling Performance Modeling for GFRP Composites," Procedia Materials Science, vol. 6, pp. 544-550, 2014.

[24] B. Panda, M. Leite, B. B. Biswal, X. Niu, and A. Garg, "Experimental and numerical modelling of mechanical properties of 3D printed honeycomb structures," Measurement, vol. 116, pp. 495-506, 2018.

[25] A. Garg, K. Tai, and B. N. Panda, "System Identification: Survey on Modeling Methods and Models," in Artificial Intelligence and Evolutionary Computations in Engineering Systems, pp. 607-615, Springer, Singapore, 2017. 


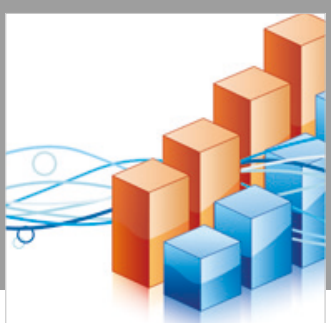

Advances in

Operations Research

\section{-n-m}
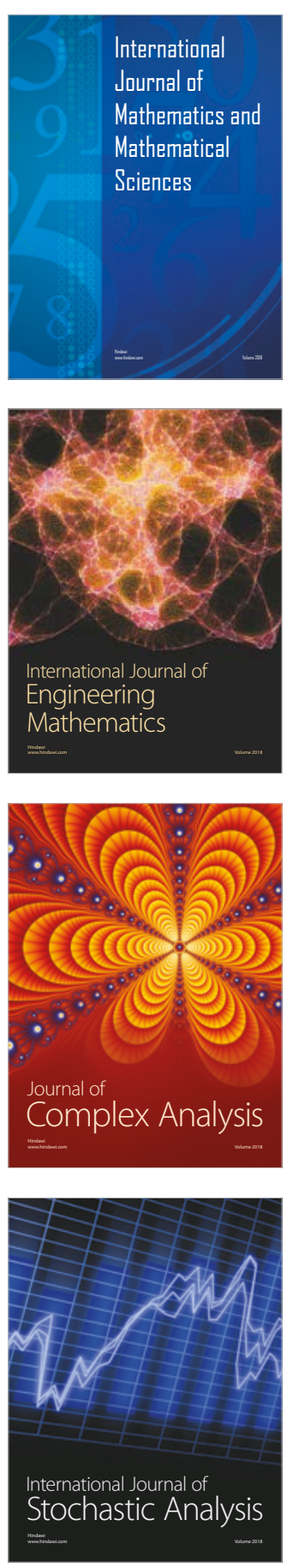
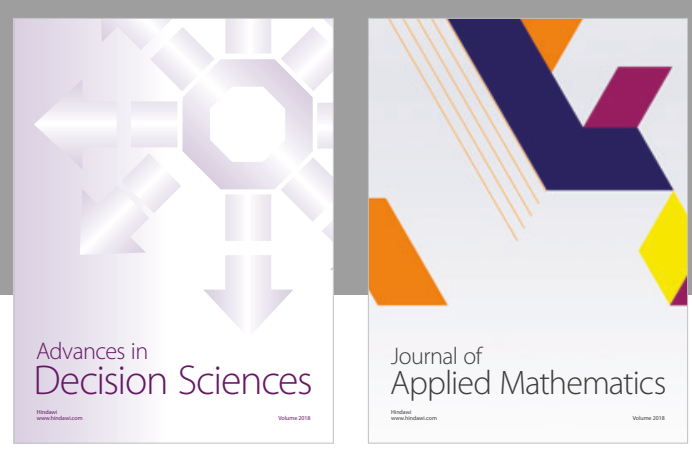

Journal of

Applied Mathematics
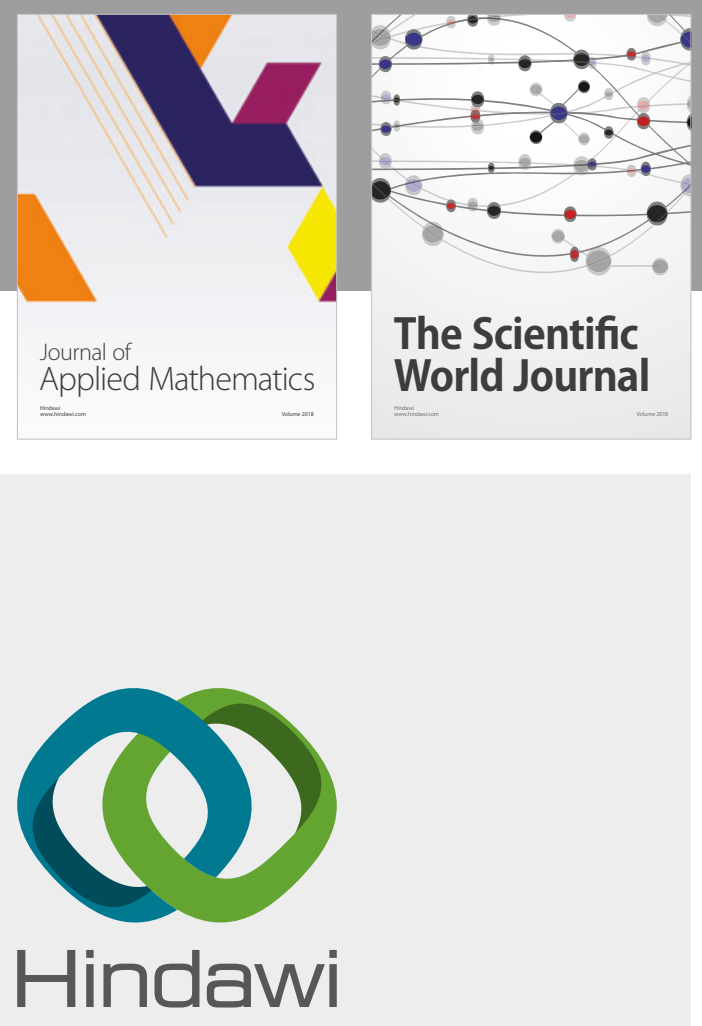

Submit your manuscripts at

www.hindawi.com

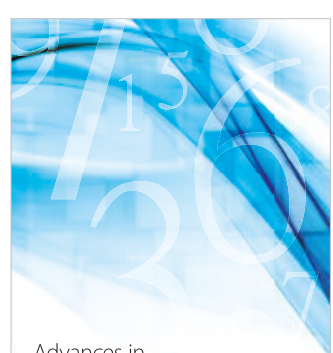

Advances in
Numerical Analysis
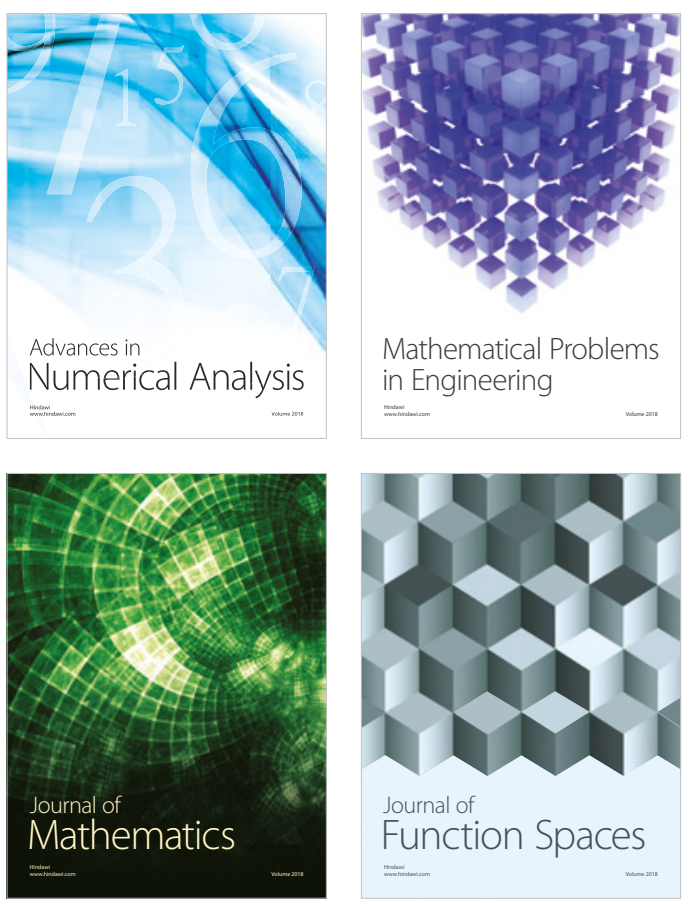

Mathematical Problems in Engineering

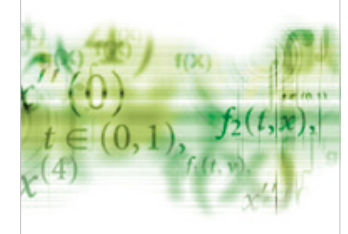

International Journal of

Differential Equations

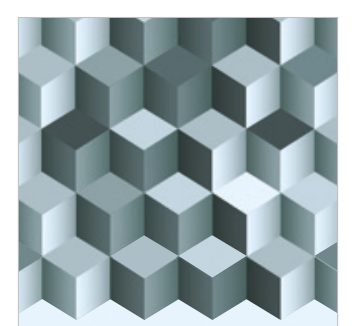

Journal of

Function Spaces
The Scientific

World Journal

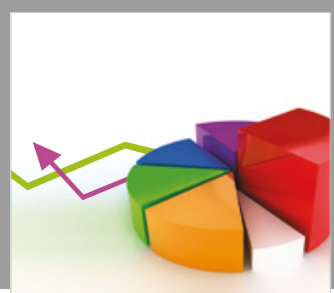

Journal of

Probability and Statistics
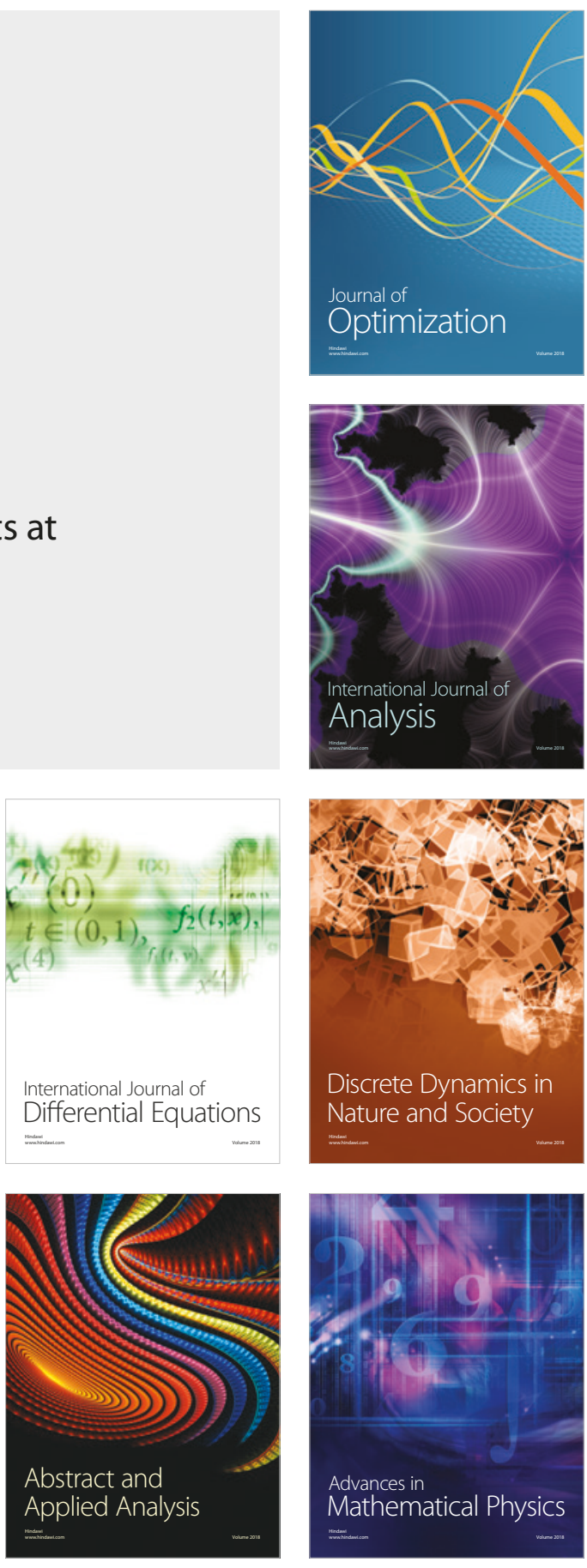